\title{
Does the maturation of early sleep patterns predict language ability at school entry? A Born in Bradford study
}

\author{
Victoria C. P. KNOWLAND ${ }^{1}$, Sam BERENS ${ }^{2}$ (D) M. Gareth GASKELL ${ }^{1}$, Sarah A. WALKER ${ }^{1}$, \\ and Lisa-Marie HENDERSON ${ }^{1}$ \\ ${ }^{1}$ Department of Psychology, University of York, York, YO10 5DD, UK and ${ }^{2}$ School of Psychology, \\ University of Sussex, Falmer, BN1 9QH, UK \\ Address for correspondence: Victoria C. P. Knowland victoria.knowland@york.ac.uk
}

(Received 15 May 2019; revised 30 September 2020; accepted 8 October 2020;

first published online 3 February 2021)

\begin{abstract}
Children's vocabulary ability at school entry is highly variable and predictive of later language and literacy outcomes. Sleep is potentially useful in understanding and explaining that variability, with sleep patterns being predictive of global trajectories of language acquisition. Here, we looked to replicate and extend these findings. Data from 354 children (without English as an additional language) in the Born in Bradford study were analysed, describing the mean intercepts and linear trends in parent-reported daytime and night-time sleep duration over five time points between 6 and 36 months-ofage. The mean difference between night-time and day-time sleep was predictive of receptive vocabulary at age five, with more night-time sleep relative to day-time sleep predicting better language. An exploratory analysis suggested that socioeconomic status was predictive of vocabulary outcomes, with sleep patterns partially mediating this relationship. We suggest that the consolidation of sleep patterns acts as a driver of early language development.
\end{abstract}

\section{Introduction}

Through the infant and pre-school years, children's vocabulary skills show substantial heterogeneity. Given that early vocabulary ability is predictive of school-age language and reading performance (Duff, Reen, Plunkett \& Nation, 2015; Lee, 2011; Psyridou, Eklund, Poikkeus \& Torppa, 2018), it is important to explore potential sources of this variability. One poorly understood, but promising, area of research is into the role of early sleep in the development of language. Here, associations will be considered between sleep over the first three years of life and receptive vocabulary ability at school entry using cohort data from the Born in Bradford study. 


\section{Day-time sleep in infancy}

Sleep plays a well-established role in supporting declarative memory consolidation across the life-span. The acquisition of new language provides one example of such learning, as laid out by the complementary learning systems approach (McClelland, McNaughton \& O’Reilly, 1995; see Davis \& Gaskell, 2009 for an application to language). When infants sleep shortly after exposure to a new word, they typically show better learning for that word at re-test compared to those who stay awake for the same interval (see Horváth $\&$ Plunkett, 2018). For example, at around 6 months of age, a day-time nap after learning has been associated with both improved generalisation of labels to new category exemplars (Friedrich et al., 2017), and a greater likelihood of extracting word forms from an artificial language through statistical learning (Simon et al., 2017). This generalisation advantage with day-time sleep persists between 9 and 16 months of age (Friedrich, Wilhelm, Born \& Friederici, 2015; Gómez, Bootzin \& Nadel, 2006; Hupbach, Gómez, Bootzin \& Nadel, 2009). Napping within a few hours of learning new linguistic information is not only associated with improved task performance that same day, but also 24 hours later (Hupbach et al., 2009). This suggests that regular sleep may be instrumental in the slow process of lexical development over infancy, with the opportunity to consolidate new information off-line soon after learning resulting in a benefit that persists even after a subsequent night of sleep. Importantly, behavioural gains in performance after a nap positively correlate with expressive vocabulary size in 16-month-olds (Horváth, Myers, Foster \& Plunkett, 2015), such that individual differences in the benefit of sleep may be associated with longer-term changes in language acquisition. However, the relationship between sleep and language development may not be as simple as more sleep means better language.

\section{Developmental trajectories of sleep}

From the age of around 18 months, children's sleep patterns start to undergo a dramatic shift from polyphasic to monophasic as children are gradually able to sleep through the night and drop their day-time naps (see Iglowstein, Jenni, Molinari \& Largo, 2003). Most children achieve monophasic sleep by 4 years of age in cultures where day-time napping is not the norm. The age at which children drop their naps varies considerably, as does total sleep time over 24 hours, particularly earlier in infancy; though variability in total sleep time reduces as monophasic sleep becomes more common (Blair et al., 2012; Iglowstein et al., 2003). While much of this variability is likely to be driven by child-internal factors, there are child-care practices and cultural norms (Crosby, LeBourgeois \& Harsh, 2005) which will also affect the sleep patterns of young children. Notably, children who show more persistent napping habits do not typically sleep for longer over 24 hours (e.g., Lam, Mahone, Mason \& Scharf, 2011). Indeed, at around 34 months of age, habitually napping pre-schoolers have been shown to sleep for 69 minutes less at night compared to their non-napping peers, with shorter night-time sleep in this group being associated with later peak melatonin production in the evening (Akacem et al., 2015).

Not only do lab-based studies suggest an active role for sleep in language learning over infancy, but there is some suggestion that the maturation of sleep patterns predicts vocabulary growth on a global scale. A number of studies have presented convincing evidence that the shift from poly- to mono-phasic sleep is functionally relevant to early cognitive development. In a population-based twin cohort $(n=1,029)$, Dionne 
et al. (2011) found that the ratio of day-time:night-time sleep (henceforth SLEEP RATIO) predicted later vocabulary skill. Specifically, a shift towards monophasic sleep at 6 and 18 months predicted better parent-reported vocabulary scores at 30 months and individually-assessed receptive vocabulary at 60 months. These authors also showed that children with persistent language delays had more day-time sleep in relation to night-time sleep (higher sleep ratio) at 6 and 18 months compared with peers who fell within the normal range for language ability. Similarly, in a smaller sample $(n=60)$, a greater proportion of night-time sleep at 12 months predicted better expressive vocabulary at 26 months (Bernier et al., 2010). Day-time naps can also have a negative influence on language development in the lab, with Werchan and Gómez (2014) reporting that in 2.5 year-olds the generalisation of labels to new category exemplars was less likely in those children who took a nap shortly after learning. Finally, in support of the idea that less day-time sleep in early childhood is associated with better cognitive performance, Lam et al. (2011) found that in 3-to-5-year-old children concurrent receptive vocabulary size and auditory attention span were negatively associated with time spent asleep during the day, and positively associated with time spent asleep at night. These authors conclude that the shift from polyphasic to monophasic sleep may act as a marker of brain maturation over the pre-school years.

More recently however, Horváth and Plunkett (2016) analysed data on sleep patterns and receptive/ expressive vocabulary development in 246 children who were between 7 and 37 months at initial test. In contrast to previous results, here the number of day-time naps positively predicted receptive vocabulary growth, while longer night-time sleep was associated with decreased growth of expressive vocabulary. The literature is therefore far from consistent on the question of whether day-time sleep in the pre-school years is supportive of developmental trajectories of language learning.

\section{Habitual napping}

Lab-based studies consistently show a positive association between day-time sleep and learning new language for children up to around two years, in whom habitual napping is essentially universal (although see Werchan \& Gómez, 2014). Beyond that age, associations still exist (see Axelsson, Williams \& Horst, 2016), but may be conflated by the issue of habitual napping status (e.g., Williams \& Horst, 2014). This is perhaps unsurprising given the difficulty in persuading children who no longer regularly nap to do so. If the shift to monophasic sleep is indeed a marker of brain maturation then there may well be systematic differences in cognitive status between those pre-schoolers who are and are not habitual nappers.

Kurdziel et al. (Kurdziel, Duclos \& Spencer, 2013) trained 50-month-old children ( $\mathrm{SD}=8$ months) on a visuo-spatial memory task and observed that a day-time nap protected against forgetting both the same day and 24 hours later. In this study, the benefit of napping after learning was greatest for children who habitually napped; though importantly, habitual nappers who did not nap after learning showed substantially poorer performance after the delay than non-nappers. A day-time nap was therefore beneficial to those who still regularly had one, but time awake after learning was not detrimental to those who no longer napped. This perhaps suggests that children drop their day-time sleep when they are cognitively ready to do so. By contrast, habitual napping status at 37 months was not found to influence the nap benefit shown for pre-schoolers' ability to generalise learning about a new verb to a novel actor (Sandoval, Leclerc \& Gómez, 2017). 
Evidence as to the significance of change in habitual napping status and how it relates to trajectories of learning in the pre-school years is therefore still unclear. It may be that polyphasic sleep is only beneficial to young children who are not yet cognitively mature enough to maintain information in an unconsolidated state over the course of the day. In this case, day-time sleep could indeed be considered a marker of relative brain immaturity. On the other hand, day-time naps could continue to be equally beneficial throughout childhood, allowing a window for off-line consolidation to support learning at intervals through the day. Indeed, day-time naps are associated with benefits in learning even for adults (e.g., see Ficca et al., 2010). In reality, the relationship between shifts in sleep status and cognitive function is unlikely to be so simple, with multiple influencing factors, including brain maturation, but also extending to domain, type and depth of learning, as well as environmental context.

\section{The current study}

If variability in the developmental maturation of early sleep patterns is functionally significant, then sleep trajectories could act as a marker for later cognitive or language issues. Theoretically, charting the role that dynamic shifts in sleep patterns play over childhood will contribute to our understanding of the mechanisms of early language acquisition, and will allow us to make predictions about how the process of memory consolidation changes over infancy and early childhood. In this study, data from the Born in Bradford database was accessed pertaining to day-time and night-time sleep from 6 through to 36 months, and related to receptive language ability at UK school entry.

\section{Research questions and hypotheses}

Our first research question was whether the consolidation of sleep patterns from poly- to mono-phasic over the first three years of life predicts receptive vocabulary at school entry. This question was addressed by assessing whether individual linear trends in sleep patterns between 6 and 36 months predict standardised vocabulary scores at school entry. Based on existing literature (in particular Dionne et al., 2011 and Lam et al., 2011), it was hypothesised that the rate at which sleep matures over this period would predict receptive vocabulary at school entry, with children who show a more rapid rate of sleep maturation also showing more advanced receptive vocabulary at 4-to-5 years of age.

There are likely to be multiple factors which co-vary with sleep patterns over early childhood. Here, the roles played by hyperactivity/inattention, socio-economic status and gender were considered. Between 18 months and 5 years of age there is a significant association between hyperactivity and short sleep duration, with the three key risk factors for both being: gender (being a boy), having insufficient household income, and having parents with a low level of education (Touchette et al., 2009). Self-regulation and attention also closely co-vary with language ability in early childhood (Gooch et al., 2016). As such our second research question was whether hyperactivity (as measured by the Strengths and Difficulties Questionnaire; Goodman, 1997), gender, and socio-economic status (as measured by indices of multiple deprivation), would partially explain variance in our vocabulary data. It was hypothesised that all three factors would explain some variance in our data, such that including them in our model would provide a stricter test of our primary hypothesis. 
Our third research question was whether, as a group, children with clinically poor receptive vocabulary levels at school entry would differ from their peers with respect to sleep over the first three years of life. This question was also addressed by Dionne et al. (2011) in their Canadian cohort study. The authors found that children with persistent, clinically poor vocabulary had higher sleep ratios at 6 and 18 months compared to children with typical language trajectories, with the association between sleep and language development being stronger in this group comparison than for the sample as a whole. Dionne and colleagues tentatively suggest that poor sleep consolidation could be a marker for long-term language delays. Here it was hypothesised that children who fall below the $10^{\text {th }}$ percentile with respect to receptive vocabulary at school entry would show more day-time sleep in relation to their total sleep time and/or less total sleep at any given point of measurement compared to their typically developing peers.

This research question is not independent of our first research question. However, in the event of no sample-wide associations, a group difference might still be anticipated when comparing children from the lower tail of the vocabulary distribution with peers who score within the typical range. Group differences may be informative about potentially qualitative differences in the role that early sleep plays in vocabulary development for some children; it would also have particular clinical significance, as change in sleep profiles over infancy could act as one of multiple markers for the later diagnosis of developmental language issues, signalling the need for early intervention.

\section{Method}

Born in Bradford (BiB) is a longitudinal birth cohort study, which is tracking 13,858 children born between April 2007 and June 2011 in the UK city of Bradford. Child health, wellbeing and educational progress are being measured from birth through to adulthood to understand the impact of multiple environmental, psychological and genetic factors. The cohort represents a diverse range of ethnicities and socio-economic status. Ethical approval for $\mathrm{BiB}$ data collection was granted by Bradford Research Ethics Committee. The current study conforms with data privacy requirements set out in the General Data Protection Regulation, 2018.

Access was granted to data from the Born in |Bradford 1,000 database, which consists of data collected from a sub-sample of around 1,000 children and includes extensive information from parental questionnaires. The children who form this $\mathrm{BiB} 1000$ cohort were born within approximately one calendar year, from August 2008 to October 2009. Children were eligible for inclusion in the BiB1000 study if their mother had completed a baseline questionnaire for the pregnancy. $41 \%$ of children eligible for inclusion into the $\mathrm{BiB} 1000$ database were recruited to it. The key predictor variables in the current analysis, taken from the BiB1000 questionnaire data, were hours spent in sleep during the day-time and night-time at five time-points: 6 months, 12 months, 18 months, 24 months and 36 months. The number of data points varies at each administration of the questionnaire: at 6 months, 1,327, at 12 months, 1310, at 18 months, 1,292, at 24 months, 1,219 and at 36 months, 1,232. Estimates of sleep time are provided by parents to the nearest hour and are likely to represent habitual sleep patterns over the previous few days or weeks. Our key outcome variable was standard score on the British Picture Vocabulary Scale-2 ${ }^{\text {nd }}$ Edition (BPVS-2; Dunn et al., 1997), which measures receptive 
vocabulary, during the first (reception) year of school. Access was also granted to the hypothesised covariates: socio-economic status, as measured by indices of multiple deprivation (IMD) from 2010, when children were 0-3 years of age, the Hyperactivity subscale from the Strengths and Difficulties Questionnaire at school entry (filled in by the class teacher), and gender.

\section{Planned confirmatory analysis}

All planned confirmatory analyses are set out in an R Markdown script (version 0.1.90; RStudio and Inc., 2014; DOI 10.17605/OSF.IO/U4YWA), which details the analysis pipeline and was tested with a small subsample of 30 data points from the dataset at Stage One of this registered report. These 30 data points were included in the confirmatory analysis as they were not used to determine sample size or to establish hypotheses, but were rather accessed in order to accurately set up the analysis. Raw data cannot be made available, in accordance with the data-sharing agreement set out by the Born in Bradford research foundation management team.

To analyse the relationships between sleep and later language skill, changes in individual sleep patterns were calculated over the five time points represented in the data; individual trajectories were then used to predict receptive vocabulary ability (BPVS-2 score) at school entry. The covariates hyperactivity, IMD, and gender were added to the model in order to establish whether any of these provided additional predictive power. Finally, children who fell below the $10^{\text {th }}$ percentile on the BPVS at school entry were sub-setted and matched to typically developing peers to consider whether sleep parameters in infancy and early childhood differ between the groups. Children who had English as an additional language were excluded from all planned analyses as information was not available regarding the extent of exposure that these children had to spoken English prior to starting school (see Supplementary Materials for a separate analysis of these individuals). It is assumed that any missing data are missing completely at random, and not as a function of either measured or non-measured characteristics. Eligible children were included in the analysis if they provided data at a minimum of three of the five waves of data collection.

\section{Confirmatory model specification}

Hypothesis 1: the rate at which sleep matures will predict receptive vocabulary at school entry

Our main sleep parameters of interest were total sleep time (TST) and the difference between day-time and night-time sleep (DIF) at five different time-points. Data were analysed using $\mathrm{R}$ ( $\mathrm{R}$ Core Team, 2017). For each participant, two linear trends were fitted to these data in order to characterize: a) the average TST and DIF across all time-points (denoted TST_B0 and DIF_B0 respectively), and b) the rate of change in TST and DIF in units of sleep hours per month (denoted TST_B1 and DIF_B1 respectively). Individual linear trends were established to avoid making assumptions about distributions before accessing data, and because it can be assumed that parental estimates of sleep time will be approximate (Bauer \& Blunden, 2008). These intercept and slope parameters were then entered into a linear regression model that predicted BPVS scores at the final time-point. As well as including the B0 and B1 terms as separate predictors, the model also specified a subset of the interactions 
Table 1. Hypotheses associated with each model term.

\begin{tabular}{|c|c|c|c|}
\hline & Term & Sign & Hypothesis \\
\hline 1 & TST_BO & + & $\begin{array}{l}\text { More sleep over infancy positively predicts } \\
\text { vocabulary at 5yrs }\end{array}$ \\
\hline 2 & TST_B1 & - & $\begin{array}{l}\text { More rapid decrease in overall sleep positively } \\
\text { predicts vocabulary at 5yrs }\end{array}$ \\
\hline 3 & DIF_BO & + & $\begin{array}{l}\text { More night-time compared to day-time sleep } \\
\text { positively predicts vocabulary at 5yrs }\end{array}$ \\
\hline 4 & DIF_B1 & + & $\begin{array}{l}\text { More rapid increase in night-time compared to } \\
\text { day-time sleep positively predicts vocabulary at } \\
5 y \text { rs }\end{array}$ \\
\hline 5 & TST_BO*DIF_B0 & + & $\begin{array}{l}\text { The effects of more total sleep and more night-time } \\
\text { compared to day-time sleep are amplified when } \\
\text { they co-occur }\end{array}$ \\
\hline 6 & TST_B1*DIF_B1 & - & $\begin{array}{l}\text { The effects of decreasing total sleep time and } \\
\text { increasing night-time compared to day-time } \\
\text { sleep are amplified when they co-occur }\end{array}$ \\
\hline 7 & TST_B0 * DIF_B1 & + & $\begin{array}{l}\text { The effects of more overall sleep and increasing } \\
\text { night-time compared to day-time sleep are } \\
\text { amplified when these co-occur }\end{array}$ \\
\hline 8 & TST_B0*TST_B1*DIF_B1 & - & $\begin{array}{l}\text { The effects of term } 7 \text { are amplified given a faster } \\
\text { decrease in total sleep time }\end{array}$ \\
\hline
\end{tabular}

between them (see Table 1). Each of these interactions tests a specific hypothesised relationship between the average amount of sleep (B0 terms) and the rate of sleep maturity (B1 terms). However, the main a priori hypothesis of interest concerns TST_B0*DIF_B1, which tests whether change in the difference between night-time and day-time sleep (DIF_B1) and the average amount of sleep per child (TST_B0) interact to influence BPVS-2 score substantially more than either TST or DIF alone. This interaction between TST and DIF terms acts as an approximation of the sleep ratio measure used in previous studies, but is more stable in the face of outliers. All interaction terms specified in Table 1 were included in the maximal model. Each interaction, starting with the highest order, was then removed and the Bayesian Information Criterion (BIC; Schwartz, 1978) of the resulting model compared with the most parsimonious existing model. Wherever the removal of interactions resulted in a decrease in BIC value equal to or greater than two, the interaction remained excluded from the model.

Hypothesis 2: sex, socioeconomic status and hyperactivity will explain variance in vocabulary scores above and beyond the variance explained by sleep patterns

From the most parsimonious baseline model, as described above, a conditional model was built by adding all three predicted covariates: Sex, IMD and Hyperactivity. For the purpose of the current data, all three of these were treated as time-invariant covariates as, although IMD and Hyperactivity may well change over time, data were only available from one time point. Each covariate was removed individually, and the BIC of the 
resulting model compared with the most parsimonious existing model. Again, wherever the removal of a term resulted in a reduction of the BIC by two or more, the term remained excluded from the model.

Hypothesis 3: children with a standard BPVS score below the $10^{\text {th }}$ percentile will, as a group, show more day-time sleep in relation to their total sleep time and/or less total sleep compared to peers with vocabulary scores in the typical range.

To test this hypothesis, children with standardised BPVS scores at or below the $10^{\text {th }}$ percentile (standard score of $\leqslant 81$ ) were sub-setted and matched to control participants on the basis of sex and IMD using pairwise propensity score matching. These groups were then compared with respect to TST and DIF using independent samples t-tests.

\section{Results}

\section{Descriptive statistics}

In total $1,538^{1}$ individuals were entered into the analysis: of those, 1,322 provided data from three or more time points. From this set, 620 did not have English as an additional language (EAL) when they entered school, and so formed our final sample. These 620 children (294 boys, 320 girls, 6 of unknown sex) are described here. 382 children contributed five data points, 147 contributed four and 91 contributed three. The median national IMD decile for the sample was $2(\mathrm{IQR}=3)$, and the local IMD decile within Bradford was $4(\mathrm{IQR}=4)$. IMD is calculated based on factors such as average education and income within a small geographic area, such that these values give an approximation of socio-economic status for each participant relative to the country and the local vicinity of Bradford respectively (where 1 represents the lowest decile and 10 the highest). Nearly all the children (604) were first born, the remaining had a single older sibling. The maternal ethnicity of 428 children was reported as 'white', for 162 'Asian or British Asian', while the remaining 30 fell into other ethnic categories. 84 mothers moved to the UK from abroad before the birth of their child; the mean age at moving was 18.22 years $(\mathrm{sd}=9.15) .217$ mothers reported that they smoked cigarettes at three months pregnant. 553 children were breastfed for at least one day; the mean number of days being breastfed was 86.17, a little under three months (sd =96.94). Median Apgar score (Apgar, 1953) at five minutes after birth (to give an indication of the health of the cohort soon after birth as rated on a ten point scale by the attending midwife or doctor) was 9, with a minimum of 6 and a maximum of 10 across the sample. At school entry, 155 children were in receipt of free school meals (25\% of the sample, and slightly higher than the average for Yorkshire \& Humber in 2013, which was 19\% see Education DataLab, 2016), 11 had an Education Health and Care Plan, and a further 102 had other support for special educational needs (SEN) in school.

Based on the work of Iglowstein and colleagues (Iglowstein, Jenni, Molinari \& Largo, 2003) we would expect to see a small increase in night-time sleep from a mean of around 11.0 hours to a mean of around 11.4 hours over the period of 6-to-36 months, and a decrease in day-time sleep from 3.4 hours to 1.7 hours over the same period. In our data, an increase in night-time sleep was observed from 9.68 to 10.05 hours, with the mean at 36 months over an hour less than expected. This increase was significant across the 30 months over which sleep was recorded $(F(4,2760)=$ 
Table 2. Sleep parameters. Mean number of hours and standard deviation (sd) for Night and Day sleep, as well as total sleep time (TST) and Night sleep - Day sleep (DIF) at 6, 12, 18, 24 and 36 months. Data are shown for all children with at least three data points (up to 620 at each observation), and for those with at least three data points and BPVS-2 score at school entry (up to 354 per observation).

\begin{tabular}{|c|c|c|c|c|c|c|c|c|c|}
\hline & \multirow[b]{2}{*}{ Month (n) } & \multicolumn{2}{|c|}{ Day sleep } & \multicolumn{2}{|c|}{ Night sleep } & \multirow{2}{*}{$\begin{array}{c}\text { TST } \\
\text { Mean }\end{array}$} & \multirow[b]{2}{*}{ sd } & \multirow{2}{*}{$\begin{array}{c}\text { DIF } \\
\text { Mean }\end{array}$} & \multirow[b]{2}{*}{ sd } \\
\hline & & Mean & $\mathrm{Sd}$ & Mean & sd & & & & \\
\hline \multirow{5}{*}{$\begin{array}{l}\text { All with }>2 \\
\text { data points }(620)\end{array}$} & $6(540)$ & 3.34 & 1.63 & 9.68 & 1.65 & 13.02 & 1.95 & 6.35 & 2.64 \\
\hline & $12(552)$ & 2.98 & 1.48 & 9.90 & 1.59 & 12.87 & 1.67 & 6.92 & 2.59 \\
\hline & $18(567)$ & 2.90 & 1.41 & 9.79 & 1.47 & 12.69 & 1.43 & 6.88 & 2.50 \\
\hline & $24(541)$ & 2.53 & 1.62 & 9.83 & 1.59 & 12.36 & 1.52 & 7.30 & 2.83 \\
\hline & $36(565)$ & 1.82 & 1.51 & 10.05 & 1.28 & 11.87 & 1.21 & 8.23 & 2.52 \\
\hline \multirow{5}{*}{$\begin{array}{l}\text { Children with } \\
\text { BPVS-2 scores (354) }\end{array}$} & $6(320)$ & 3.30 & 1.58 & 9.67 & 1.58 & 12.97 & 1.90 & 6.37 & 2.53 \\
\hline & $12(315)$ & 3.04 & 1.53 & 9.85 & 1.55 & 12.89 & 1.75 & 6.80 & 2.52 \\
\hline & $18(321)$ & 2.92 & 1.38 & 9.75 & 1.35 & 12.67 & 1.38 & 6.83 & 2.36 \\
\hline & $24(314)$ & 2.62 & 1.81 & 9.71 & 1.76 & 12.33 & 1.58 & 7.09 & 3.20 \\
\hline & 36 (323) & 1.79 & 1.45 & 10.03 & 1.31 & 11.82 & 1.20 & 8.24 & 2.49 \\
\hline
\end{tabular}

4.42, $\mathrm{p}=0.002$ ). Reported day-time sleep decreased from 3.34 hours at six months to 1.82 hours at 36 months, in line with expectations, and again this change was significant across the timespan of our sample $(\mathrm{F}(4,2760)=78.70, \mathrm{p}<0.001)$. Table 2 gives values for caregiver-estimated Night sleep and Day sleep across the five data collection points $(6,12,18,24 \& 36$ months), as well as total sleep time (TST) and the difference between Night and Day sleep (DIF). Finally, we tested our assumption that the TST_B1 and DIF_B1 statistics were able to characterise rates of change in sleep duration across time points. If so, the average slope across participants should be significantly different from zero, suggesting a non-zero rate of change in TST and DIF scores. One sample $t$-tests revealed that this was indeed the case for both TST_B1 $(d=-0.51, t(619)=-12.64, p<0.001)$ and DIF_B1 $(d=0.49, t(619)=$ $12.12, p<0.001$ ) (see Figure 1).

Around their $5^{\text {th }}$ birthday, two years after the final sleep measure (as part of the Starting School dataset) the BPVS-2 (Dunn et al., 1997) was carried out with 354 children from our sample at a mean chronological age of 59.06 months $(\mathrm{sd}=3.61)$. The mean standardised score for the sample was $104.76(\mathrm{sd}=15.20)$, with a minimum standard score of 39 and a maximum of 160 . As 266 children did not have a measure of receptive vocabulary, they were unable to form part of our confirmatory models. Sleep parameters for this sample of 354 are given in Table 2, and again TST_B1 and DIF_B1 statistics were able to characterise rates of change in sleep duration across time points (TST_B1 $(d=-0.54, t(353)=-10.23, p<0.001)$ and DIF_B1 $(d=0.49, t(353)=$ $9.28, p<0.001)$ ). For this sample of 354 , median national IMD decile was $2(\mathrm{IQR}=3)$, and local IMD decile within Bradford was $4(\mathrm{IQR}=4) .89$ children were in receipt of free school meals (again, 25\% of the sample). Five children had an Education Health and Care Plan, and a further 64 had other support for SEN in school; $19.5 \%$ of the sample therefore had identified SEN, compared to $15.4 \%$ of pupils in the UK overall who had SEN in 2015 (DoE, 2015), and 17.5\% in Bradford (Bradford City Council, 

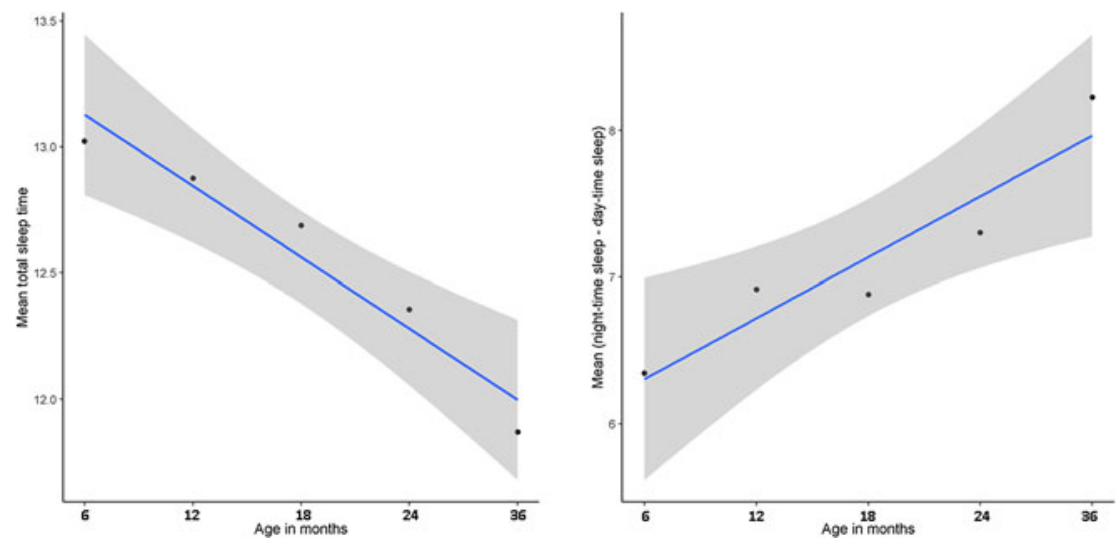

Figure 1. Average slope for TST_B1 and DIF_B1 statistics characterising rates of change in sleep duration across time points (age in months).

2018). The Born in Bradford cohort as a whole has been shown, elsewhere, to be representative of the population of Bradford (Wright et al., 2013).

\section{Confirmatory models}

Hypothesis 1: the rate at which sleep matures will predict receptive vocabulary at school entry

Three-way and two-way interaction terms were successively removed from the model (as described under 'confirmatory model specification' above), leaving four single terms: the intercept and the slope for total sleep time (TST) and for the difference between night-time and day-time sleep (DIF). The model significantly predicted BPVS standard scores at school entry $(\mathrm{F}(4,349)=4.682, \mathrm{p}=0.001)$, with the only significant predictor being the (mean) intercept of DIF (see Figure 2). The more time spent asleep during the night compared to the day between 6 and 36 months of age, the better receptive vocabulary outcomes at age five (see Table A1 in Appendix A for model details).

As DIF_B0 emerged as the only significant predictor of receptive vocabulary, we added an exploratory model to determine whether any given data collection point was particularly relevant to language development. A model with DIF scores at each time point significantly predicted BPVS scores, as anticipated $(\mathrm{F}(5,219)=3.91, \mathrm{p}=0.002)$. Only the score at 12 months emerged as significant $(t=2.02)$, with the score at 6 months trending towards significance $(\mathrm{t}=1.83)$ (see details in Table A2, Appendix A).

Hypothesis 2: sex, socioeconomic status and hyperactivity will explain variance in vocabulary scores above and beyond the variance explained by sleep patterns

From the most parsimonious confirmatory model (as described above), we added the co-variates IMD, Hyperactivity and Sex. This model significantly predicted BPVS $(\mathrm{F}(7,262)=2.62, \mathrm{p}=0.0126)$, with DIF_B0 remaining significant $(\mathrm{t}=2.52)$, and IMD $(\mathrm{t}=2.05)$ emerging as an additional predictor (see Figure 3$)$. This model with 


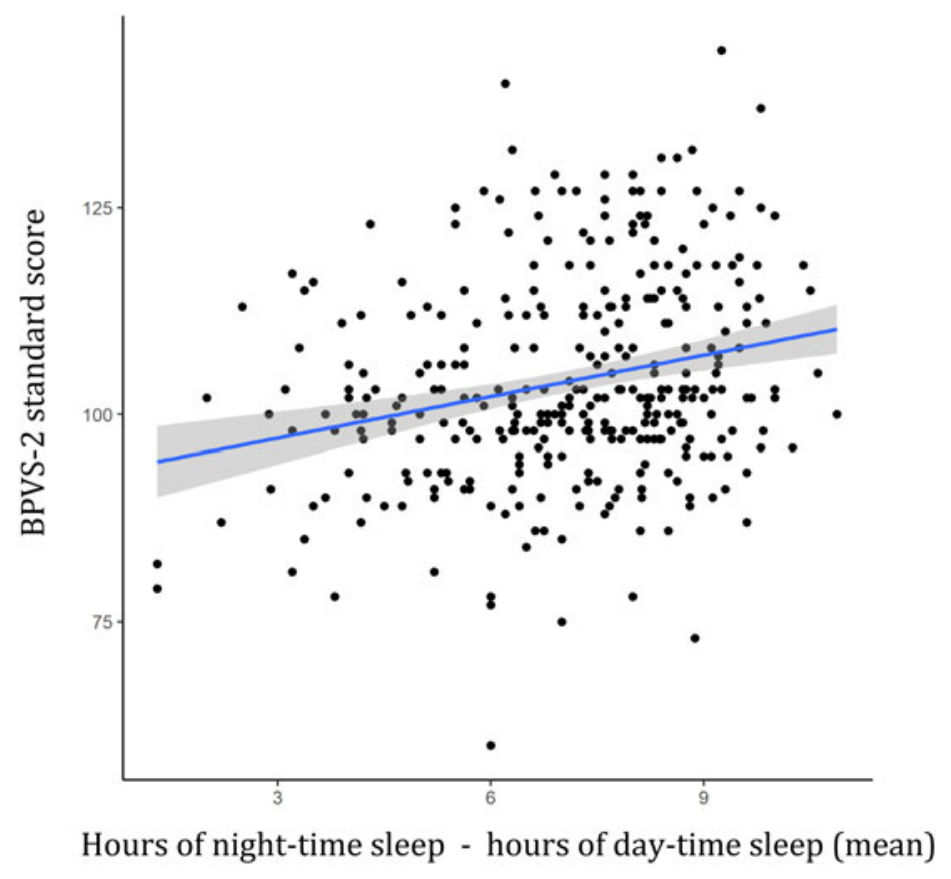

Figure 2. Relationship between DIF_B0 age 6-36 months and BPVS-2 standard score at age five.

additional covariates improved data fit (BIC without covariates $=2947.13$, BIC with covariates $=2265.64)$. However, as 84 participants did not have hyperactivity data from the Strengths and Difficulties Questionnaire, we re-ran the model excluding this variable. The removal of this variable was not planned or anticipated and should therefore be considered exploratory. The predictors DIF_B0 and IMD remained significant in this model, referred to henceforth as the Sleep Parameter model (BIC $=2926.24)$, which again overall predicted receptive vocabulary at age five $(\mathrm{F}(6,344)$ $=4.43, \mathrm{p}<0.001$ (see Table A3 in Appendix A).

In order to remove overly influential cases, DFBETAS (Belsley, Kuh \& Welsch, 1980) were calculated using the package 'influence.ME' (version 0.9; Nieuwenhuis, Pelzer \& te Grotenhuis, 2012). Fifteen participants were removed on account of DFBETAS exceeding \pm 3.29 standard deviations from the mean for either variable of interest or the intercept. Running the Sleep Parameters model again $(\mathrm{F}(6,329)=5.089, \mathrm{p}<0.001)$ confirmed that both DIF_B0 and IMD remained significant predictors, as can be seen in Table 3.

We have 55.7 observations for each term in our final model. To ensure that it is appropriate to interpret significant effects, we assessed effect sizes with semi-partial correlations for each of the independent variables that significantly contributed to the model. Both semi-partial correlations were above 0.1 (DIF_B0 with BPVS_SS, $\mathrm{r}=.19, \mathrm{p}=<0.001 ;$ IMD with BPVS_SS, $\mathrm{r}=.16, \mathrm{p}=0.004)$, and were therefore deemed to be of theoretical interest. Substantial multicolinearity was ruled out by calculating variance inflation factors, which ranged from 1.01 to 1.13 . Although the final sample size obtained was substantially smaller than we had anticipated at Stage One of this report (anticipated $\mathrm{N}=\sim 700$, observed $\mathrm{N}=354$ ), a-priori power analysis 


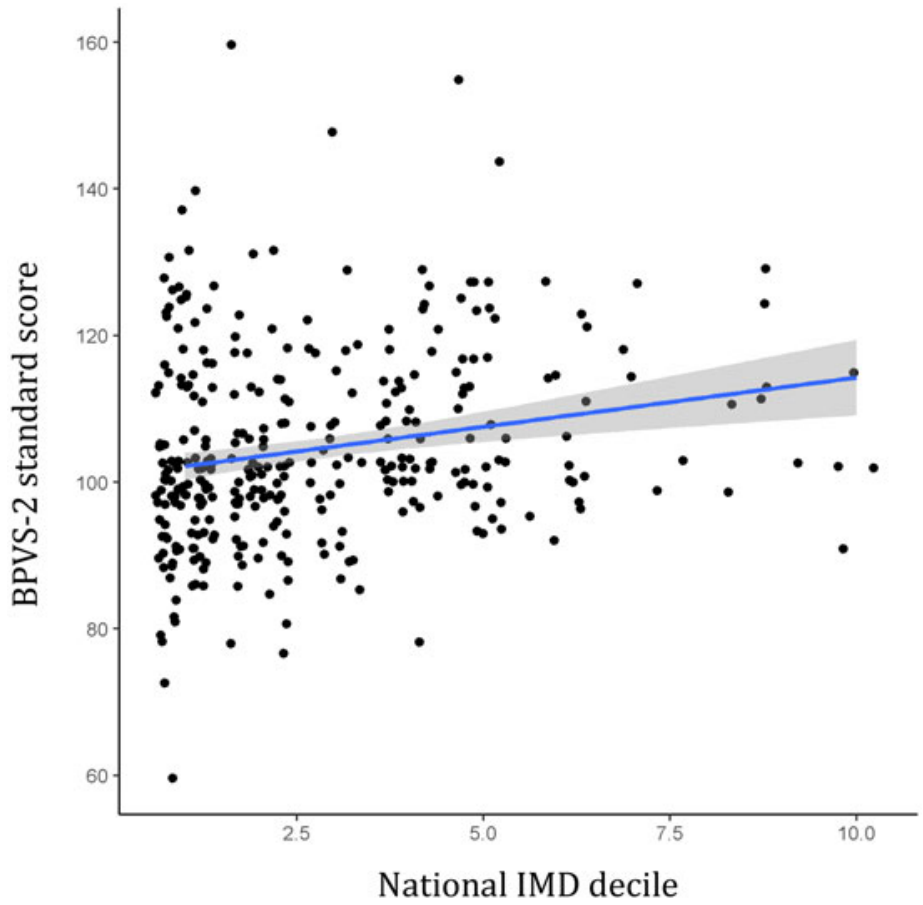

Figure 3. Relationship between national IMD decile (higher indicates less deprived) and BPVS-2 standard score at age five.

Table 3. Sleep Parameters intercept (B0) and slope (B1) for total sleep time (TST) and the difference between night sleep and day sleep (DIF) over 6-36 months of age, plus national IMD decile and Sex predicting BPVS standard score at age 5. Model formed from 334 participants (df =6, 329). Significance: ${ }^{\star \star *} p<0.001,{ }^{\star \star} p<0.01$. Standard error of $b$ and $95 \%$ confidence intervals are given as bootstrap statistics over 1,000 re-samples.

\begin{tabular}{|c|c|c|c|c|c|c|}
\hline \multirow[b]{2}{*}{ Term } & \multirow[b]{2}{*}{$b$} & \multirow[b]{2}{*}{ SE $b$} & \multirow[b]{2}{*}{$ß$} & \multicolumn{2}{|c|}{ b 95\% Cl } & \multirow[b]{2}{*}{$t$} \\
\hline & & & & Lower & Upper & \\
\hline (Intercept) & 92.92 & 8.54 & & 76.23 & 109.74 & $9.32^{\star \star \star}$ \\
\hline TST_BO & -0.15 & 0.67 & -0.01 & -1.45 & 1.16 & -0.20 \\
\hline TST_B1 & -11.30 & 7.89 & -0.07 & -28.56 & 3.54 & -1.23 \\
\hline DIF_BO & 1.39 & 0.35 & 0.20 & 0.67 & 2.04 & $3.59^{\star \star \star}$ \\
\hline DIF_B1 & -6.23 & 4.92 & -0.06 & -16.02 & 3.26 & -1.03 \\
\hline IMD & 1.08 & 0.32 & 0.17 & 0.43 & 1.70 & $3.03^{\star \star}$ \\
\hline Sex & 1.06 & 1.49 & 0.04 & -1.78 & 4.12 & 0.74 \\
\hline
\end{tabular}


based on effect sizes of theoretical interest being $\mathrm{f}^{2}=0.11(\mathrm{r}=0.1)$, suggest that a model with eleven predictors (all hypothesised terms plus covariates) would require an $\mathrm{N}$ of 239 to achieve $90 \%$ power.

Hypothesis 3: children with a standard BPVS score below the $10^{\text {th }}$ percentile will, as a group, show more day-time sleep in relation to their total sleep time and/or less total sleep compared to peers with vocabulary scores in the typical range.

As fewer children than anticipated were included in our models, only 12 could be identified as falling below the $10^{\text {th }}$ percentile on the BPVS at age 5. Nevertheless, these 12 were matched by Sex and IMD to 12 children who fell within the typical range of the BPVS. The four sleep parameters included in the models described above (TST_B0, TST_B1, DIF_B0, DIF_B1) were compared across groups, revealing no significant differences (see Table 4).

\section{Exploratory models}

\section{Mediation analysis}

In our hypotheses we anticipated that adding hyperactivity to our model would improve fit by virtue of this factor potentially mediating the relationship between sleep and vocabulary development; we planned to add socioeconomic status and sex to the model as they are known to predict hyperactivity. In the event, we were unable to add hyperactivity to the model because of data loss, however, socioeconomic status (IMD) was found to significantly predict vocabulary when controlling for our sleep variable of interest (DIF_B0). We decided to explore this relationship further by asking whether the difference between night-time and day-time sleep might be mediating a relationship between IMD and receptive vocabulary. Socioeconomic status has long been recognised as a predictor of language development (see Demir \& Küntay, 2014 and Schwab \& Lew-Williams, 2016 for reviews of the neurocognitive and behavioural associations respectively). The relationship between SES and language development has been proposed to operate via child characteristics, environmental resources or aspects of parent-child interaction (see Pace, Luo, Hirsh-Pasek \& Golinkoff, 2017). SES is also known to predict aspects of sleep behaviour in older children, such as sleep hygiene, sleep efficiency and total sleep time (e.g., El-Sheikh et al., 2013).

Here, we decided to investigate the possibility that the relationship between IMD and BPVS-2 standard scores at school entry was partially mediated by our sleep variable of

Table 4. Mean (and standard deviation) for each sleep parameter for 12 children falling below $10^{\text {th }}$ percentile on BPVS and 12 matched controls. Mann Whitney $U$ statistic is given along with $p$ value.

\begin{tabular}{lcccccc}
\hline Group & & TST_B0 & TST_B1 & DIF_B0 & DIF_B1 & BPVS_SS \\
\hline $\begin{array}{l}\text { BPVS }>10^{\text {th }} \\
\text { percentile }\end{array}$ & Mean (sd) & $12.46(1.21)$ & $-0.04(0.11)$ & $6.54(1.87)$ & $0.11(0.11)$ & $104.75(18.24)$ \\
\hline $\begin{array}{l}\text { BPVS }<10^{\text {th }} \\
\text { percentile }\end{array}$ & Mean (sd) & $12.82(0.70)$ & $-0.05(0.07)$ & $6.01(2.64)$ & $0.09(0.07)$ & $69.92(12.09)$ \\
\hline $\mathrm{U}(p)$ & $50.5(0.23)$ & $90(0.32)$ & $80.5(0.64)$ & $93(0.24)$ & $144(<0.001)$ \\
\hline
\end{tabular}




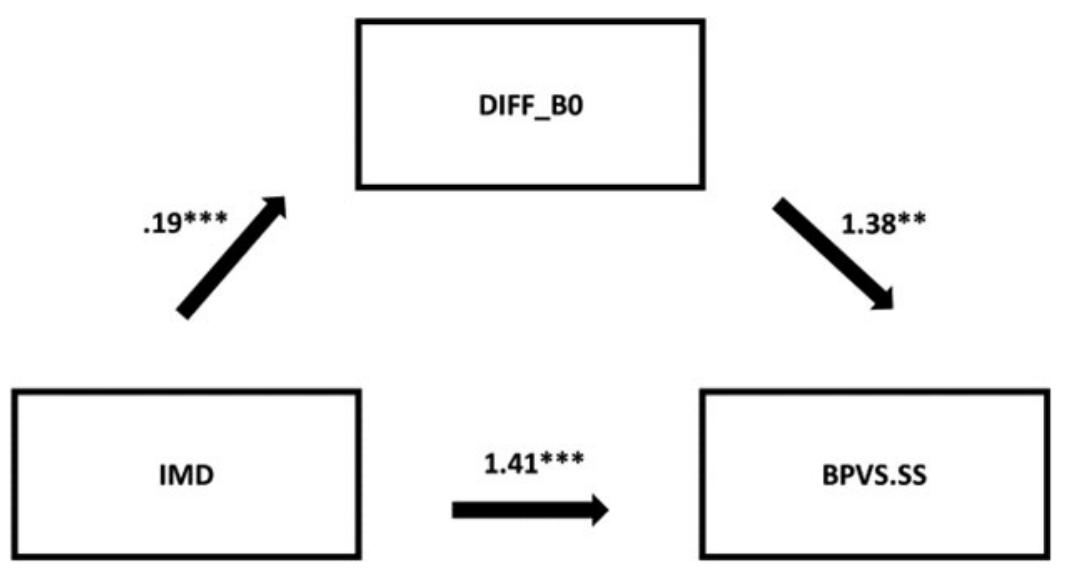

Figure 4. Partial mediation of the relationship between IMD and BPVS-2 standard scores at school entry by the mean difference between night and day sleep at 6-36 months. Unstandardised regression coefficients shown. Significance ${ }^{* *} p<0.001,{ }^{* *} p<0.01$.

interest: namely, the mean difference between night and day sleep (see Figure 4). The effect of IMD on BPVS-2 outcomes was indeed found to be partially mediated by DIF_B0. We tested the significance of the indirect effect between IMD and BPVS-2, and DIF_B0 and BPVS-2 $\left(0.19^{\star} 1.38=.25\right)$ using bootstrapping procedures in $\mathrm{R}$ package 'mediation' (version 4.5.0; Tingley et al., 2014). Unstandardized indirect effects were computed for each of 1,000 bootstrapped samples. The bootstrapped unstandardized indirect effect was significant at .25 (95\% CI 0.09 and $0.47, p$ $<0.001)$. The proportion of the effect of IMD on BPVS-2 to operate via our sleep variable was estimated at $0.179(95 \%$ CI 0.060 and $0.43, \mathrm{p}<0.001)$. See Table A4 (Appendix A) for details of the models entered into the mediation analysis.

\section{Discussion}

The aim of this registered report was to contribute to the literature establishing how sleep in infancy and early childhood, and changes in sleep over that period, are relevant to language development. We hypothesised (in line with Dionne et al., 2011 and Bernier et al., 2010) that the rate at which sleep shifts from polyphasic to monophasic over 6-to-36 months would positively predict receptive vocabulary at school entry in children participating in the Born in Bradford study. We further hypothesised that hyperactivity, SES and sex would explain additional independent variance in receptive vocabulary, and that children with clinically poor levels of receptive vocabulary at school entry would show more day-time sleep in relation to their total sleep time and/or less total sleep at any given point of measurement compared to their typically developing peers.

\section{Mean difference between night-time and day-time sleep in infancy predicts receptive vocabulary outcomes at age five}

We anticipated that the interaction between mean total sleep time (TST) and the increase in the difference between night-time and day-time sleep time (Sleep DIF) 
would best capture sleep maturation over infancy and early childhood (relative to other sleep variables such as TST), and hence be most predictive of receptive vocabulary. However, the only significant predictor to emerge from our model was the mean difference between night-time and day-time sleep over the whole period of measurement. This suggests that more consolidated sleep (a higher proportion of night-time relative to total sleep) may be an indicator of advanced cognitive performance, as also demonstrated by Dionne et al. (2011), Bernier et al. (2010) and another population study, which found persistently short nocturnal sleep over infancy predicted lower language scores at two years of age (Smithson et al., 2018). It is notable that our measure of CHANGE in sleep behaviour was not predictive of language at age five, such that individuals who showed relatively consolidated sleep at each measurement point had a slight advantage at follow-up, but those who showed a greater rate of change between time points did not. A subsequent exploratory analysis suggested that the biggest driver of receptive vocabulary at age five was our Sleep DIF variable when infants were 12 months of age, with Sleep DIF at 6 months being the second biggest contributor.

There are two main ways in which these data might be interpreted, though these interpretations are not mutually exclusive. The first is that the status of infants' sleep-wake behaviour relative to peers marks individual differences in brain maturation, as suggested by Lam et al. (2011). Indeed, various features of sleep have been suggested to both drive and mark fundamental neurodevelopmental processes. Slow wave sleep parameters have been associated with changes in white matter microstructure over childhood (Kurth et al., 2017), regional grey matter volume in adolescence (Buchmann et al., 2011) and regional changes in experience-dependent plasticity, particularly in childhood (Wilhelm et al., 2014; and see Ringli \& Huber, 2011). REM sleep, which accounts for about 50\% of sleep time at birth, falling to around $25 \%$ by age three (see Huber \& Born, 2014), has been suggested to provide endogenous activity stimulating activity-dependent neuronal maturation in infants (see Ednick et al., 2009), with REM sleep deprivation being associated with loss of brain plasticity in animals (Frank, Issa \& Stryker, 2001). The second interpretation of our key finding is that sleep behaviour may actively drive language development, with consolidated night-time sleep providing an opportunity for the consolidation of new associative learning in the linguistic domain.

While our results concur with much of the literature, there is a discrepancy with the findings of Horváth and Plunkett (2016). These authors recorded sleep and vocabulary development through detailed parent diaries and parent reported language scores; they found sleep efficiency at night (but not time spent asleep) and number of naps during the day to be predictive of receptive vocabulary, as well as change in receptive vocabulary. Sleep efficiency is the percentage of time spent in bed when the individual is asleep, and has been shown to be an important predictor elsewhere. For example, toddlers with Down Syndrome who have low sleep efficiency also exhibit poorer expressive language (Edgin et al., 2015), and higher verbal IQ at 36 months in typically developing children is predicted by less disrupted sleep at night and more fragmented sleep during the day at zero and six months of age (Franco et al., 2019). It is possible then, that our Sleep DIF variable indirectly reflects the efficiency of night-time sleep. Indeed, sleep efficiency increases linearly between two and four years of age, along with a linear decrease in day-time sleep and increase in the proportion of night-time-to-total sleep (Tétreault, Bernier, Matte-Gagné \& Carrier, 2018). 
Continuous night-time sleep has been shown to support memory consolidation compared to fragmented sleep in adults (Djonlagic et al., 2012); and experimentally induced sleep fragmentation dramatically reduces slow wave sleep quantity in adults (Ferri et al., 2010). In childhood, sleep fragmentation correlates negatively with performance on cognitive tasks requiring executive control (Sadeh, Gruber \& Raviv, 2002). At ten months of age sleep efficiency correlates positively with general cognitive development, while motor activity and night waking correlate negatively (Scher, 2005), and at eight months PSG measured snore-related arousals (where no apnea was observed) correlate negatively with cognitive development (Montgomery-Downs \& Gozal, 2006). Finally, amount of time spent awake after night-time sleep onset at four and six months predicts more rapid working memory maturation over the first year of life (Pisch, Wisemann \& Karmiloff-Smith, 2019), with more time awake after sleep onset predicting slower growth.

Extant data are therefore convergent on the idea that continuous sleep supports cognitive development, although there is very little work regarding the effects of change in day-time sleep behaviour on neurophysiological sleep parameters. The one study that has considered this question (Lassone et al., 2016) found that, in children aged 30-36 months, missing a nap resulted in night-time recovery sleep that was both more efficient and contained greater slow wave activity than night-time sleep after a day containing a nap (the difference in efficiency held even when parameters of the nap sleep were taken into account). Consolidated night-time sleep may therefore provide more opportunity for slow wave sleep, and consequently more opportunity for the consolidation of new linguistic learning in infancy (Friedrich et al., 2015; 2017; Gómez et al., 2006; Hupbach et al., 2009; Simon et al., 2017). Future work is required here focusing on multi-measure approaches to capturing sleep over development to consider not only the mechanisms by which efficient sleep might support language development, but also how sleep effects play out over developmental time and across cognitive domains.

The issue of more day-time naps being predictive of better receptive vocabulary outcome in the Horváth and Plunkett data is somewhat harder to reconcile with the current results. It is of note that the current sample contrasts quite sharply with that of Horváth and Plunkett with respect to SES, with the latter data coming from a considerably more affluent population. The constraints on language development are likely to vary across samples, as are childcare options and opportunity for day-time naps; thus, it is possible that SES may moderate associations between sleep maturation and language, with the relationship between sleep and cognition differing at different levels of SES (Buckhalt, El-Sheikh \& Keller, 2007). Interactions with age and demographic factors should be carefully considered in future research.

\section{Socioeconomic status, sleep and vocabulary development}

We found that SES, as measured by national indices of multiple deprivation decile taken within the first three years of life, predicted variance in our receptive vocabulary measure at five years. This replicates many previous reports of an association between SES and language development (see Demir \& Küntay, 2014; Pace, Luo, Hirsh-Pasek \& Golinkoff, 2017; Schwab \& Lew-Williams, 2016). This association has been proposed to operate via multiple routes, including aspects of parent-child interaction such as the diversity of child-directed speech (Huttenlocher et al., 2010), and aspects of the home environment such as level of chaos (Vernon-Feagans, 
Garrett-Peters, Willoughby \& Mills-Koonce, 2012). Upon running an exploratory mediation analysis, we found that sleep partially mediated the link between SES and receptive language: children from lower SES households showed a smaller difference between time spent asleep at night versus during the day, and this tendency was associated with lower receptive language outcomes two years later.

We can only speculate as to the reason for this partial mediation. While in older children, poorer sleep in children from low SES backgrounds has been attributed to factors such as pre-sleep worry (Bagley, Kelly, Buckhalt \& El-Sheikh, 2015), of more relevance to the age of children studied here are factors such as increased bed sharing practices (which is associated with increased nocturnal wakings) (Hysing, Harvey, Torersen, Ystrom, Reichborn-Kjennerud \& Sivertsen, 2014), and less adherence to bedtime routines (Crabtree et al., 2005). As these variables were not recorded in the current dataset we cannot draw conclusions as to the origin of any effects of SES. Notably though, both IMD and our Sleep DIF variable explained additional independent variance in our outcome measure, indicating that the effects of sleep are not wholly attributable to SES, and that SES operates via more routes than sleep alone.

\section{Limitations}

The conclusions we can draw here must be considered alongside the limitations inherent to this study. Most importantly, Born in Bradford was not intended as a study of sleep, such that the data available are approximate parental reports. While these data replicate and add to the extant literature, naturally a deeper level of understanding could be achieved with more detailed sleep measurement.

The current dataset is more limited by sample size than we had anticipated, with not all children contributing BPVS-2 data: as a result, very few clinical cases emerged. Follow-up in a prospective clinical sample would be justified as there are plenty of indications that sleep is clinically important with respect to language development: Dionne et al. (2011) show that for children with clinically poor language at 60 months, day-time sleep in infancy accounted for more total sleep time than for typically developing peers; Botting and Baraka (2017) found that, according to parental report, children with developmental communication disorders had more trouble getting to sleep and tended to wake earlier than their peers; and finally, sleep disorders place children at risk for language issues, particularly in the phonological domain (McGregor \& Alper, 2015).

A final limitation to highlight is that these data are not necessarily representative of the UK population, being from a relatively low SES and ethnically diverse sample. The children represented here showed considerably shorter total sleep time (over an hour less) than has been previously reported for children of this age (Iglowstein et al., 2003). While we cannot address this here, it seems plausible that this short total sleep time may be accounted for, in part at least, by the socioeconomic status of the children included.

\section{Conclusions}

In conclusion, we suggest that the consolidation of sleep patterns acts as a driver of early language development. The change from polyphasic to monophasic sleep acts as a marker of biological changes that allow the consolidation of new linguistic material. Sleep is also implicated in neurodevelopmental changes that underlie linguistic capacity. Evidence from behavioural genetic studies (Touchette et al., 2013) suggests 
that while day-time sleep duration in infancy is strongly influenced by environmental factors, consolidated night-time sleep duration is, conversely, strongly influenced by genetic factors, such that the interplay of genetic and environmental factors may influence different aspects of the establishment of circadian and ultradian cycles. There is a clear need for detailed measurement of sleep over early development, to understand this interplay and to answer questions such as how day-time sleep in early childhood is necessary for the consolidation of information stored in the immature hippocampus (see Gómez \& Edgin, 2015); what biological mechanisms allow children to reduce day-time sleep; whether fragmented night-time sleep is beneficial in early infancy (Freudigman \& Thoman, 1993); and crucially, how parents can best support their children to develop cognitive skills by supporting sleep behaviour in a way that is sensitive to the physical, neurological and emotional needs of the child.

Acknowledgements. This work was supported by the ESRC (ES/N009924/1; ES/R007454/1). The authors would like to thank the Born in Bradford research foundation for their generosity in sharing data. Born in Bradford is only possible because of the enthusiasm and commitment of the Children and Parents in BiB. We are grateful to all the participants, health professionals and researchers who have made Born in Bradford happen. The views expressed in this paper are those of the authors and not necessarily those of the ESRC, Wellcome, and UK Department of Health and Social Care or National Health Services.

The Born in Bradford data reported in this paper was supported by a Wellcome Trust infrastructure grant (WT101597MA), a Programme Grant for Applied Research from the National Institute for Health Research (NIHR: Development and evaluation of interventions for the prevention of childhood obesity in a multi-ethnic population: the Born in Bradford NHS Research Programme RP-PG-0407-10044). Born in Bradford is support by the NIHR Applied Research Collaboration for Yorkshire and Humber. This study was supported by the Economic and Social Research Council, as part of the grant Memory consolidation in typical and atypical development. Grant reference: ES/N009924/1.

Conflicts of interest. none.

Supplementary Material. For supplementary material accompanying this paper, visit https://oi.org/10. 1017/S0305000920000677

The data that support the findings of this study are available from the Born in Bradford Research Foundation. Restrictions apply to the availability of these data, which were used under license for this study. The analysis script and output for Stage 1 and Stage 2 are available from the Open Science Framework [DOI 10.17605/OSF.IO/U4YWA]. The original manuscript approved at Stage 1 can be found at http://osfio/mb4c8/.

\begin{abstract}
Notes
${ }^{1}$ At Stage one of this registered report we anticipated an initial sample size of 1,346, based on the number of children in the BiB1000 database for whom questionnaire data was understood to be provided at three or more of the five possible time points. In the event, the number of unique respondents was actually higher than that, with not all respondents providing data at the first time point, we were therefore unable to identify the exact number of data points before exclusions prior to accessing the sleep data.
\end{abstract}

\title{
References
}

Akacem, L.D., Simpkin, C.T., Carskadon, M.A., Wright, K.P. Jr, Jenni, O. G., Achermann, P., \& Le Bourgeois, M. K. (2015). The timing of the circadian clock and sleep differ between napping and non-napping toddlers. PLoS ONE 10(4): e0125181. doi: 10.1371/journal.pone.0125181.

Apgar, V. (1953). A proposal for a new method of evaluation of the newborn infant. Current Researches in Anesthesia and Analgesia, 32:260-267. 
Axelsson, E. L., Williams, S. E., \& Horst, J. (2016). The effect of sleep on children's word retention and generalization. Frontiers in Psychology, 7: 1192. doi: 10.3389/fpsyg.2016.01192.

Bagley, E. J., Kelly, R. J., Buckhalt, J. A., \& El-Sheikh, M. (2015). What keeps low-SES children from sleeping well: the role of pre-sleep worries and sleep environment. Sleep Medicine, 16 (4): 496-502. doi: 10.1016/j.sleep.2014.10.008

Bauer, K. M., \& Blunden, S. (2008). How accurate is subjective reporting of childhood sleep patterns? A review of the literature and implications for practice. Current Pediatric Reviews, 4 (2): 132-142. doi: $10.2174 / 157339608784462025$.

Belsley, D., Kuh, E., \& Welsch, R. (1980). Regression diagnostics. Identifying influential data and sources of collinearity. Wiley, 1980. [p.39, 40, 43].

Bernier, A., Carlson, S. M., Bordeleau, S., \& Carrier, J. (2010). Relations between physiological and cognitive regulatory systems: infant regulation and subsequent executive functioning. Child development, 81: 1739-1752. doi: 10.1111/j.1467-8624.2010.01507.x.

Blair, P. S., Humphreys, J. S., Gringras, P., Taheri, S., Scott, N., Edmond, A., Henderson, J., \& Fleming, P. J. (2012). Childhood sleep duration and associated demographic characteristics in an English cohort. Sleep, 35 (3): 353-360. doi: 10.5665/sleep.1694.

Botting, N., \& Baraka, N. (2017). Sleep behaviour relates to language skills in children with and without communication disorders. International Journal of Developmental Disabilities, doi:10.1080/ 20473869.2017.1283766

Bradford City Council (2018). Bradford district's strategy for Children and Young People with Special Educational Needs and Disabilities 2018-2022. Downloaded from https://bradford.moderngov.co.uk/ documents/s21592/SEND\%20Strategy\%202018-22\%20draft\%20for\%20consultation.pdf

Buchmann, A., Ringli, M., Kurth, S., Schaerer, M., Geiger, A., Jenni, O. G., \& Huber, R. (2011). EEG sleep slow-wave activity as a mirror of cortical maturation. Cerebral Cortex, 21 (3): 607-615. doi: $10.1093 /$ cercor/bhq129

Buckhalt, J.A., El-Sheikh, M., \& Keller, P. (2007). Children's sleep and cognitive functioning: race and socioeconomic status as moderators of effects Child Development, 78 (1): 213-231. doi: 10.1111/ j.1467-8624.2007.00993.x

Crabtree, V. M., Korhonen, J. B., Montgomery-Downs, H. E., Jones, F., O’Brien, L. M., \& Gozal, D. (2005). Cultural influences on the bedtime behaviors of young children. Sleep Medicine, 6 (4): 319324. doi: 10.1016/j.sleep.2005.20.001

Crosby, B., LeBourgeois, M. K., \& Harsh, J. (2005). Racial differences in reported napping and nocturnal sleep in 2- to 8-year old children. Pediatrics, 115(1 Suppl): 225-232. doi: 10.1542/peds.2004-0815D

Davis, M.H., \& Gaskell, M.G. (2009). A complementary systems account of word learning: neural and behavioural evidence. Philosophical Transactions of the Royal Society, B, 00: 1-28. doi:10.1098/rstb.2009.0111

Demir, O. E., \& Küntay, A. C. (2014). Cognitive and neural mechanisms underlying socioeconomic gradients in language development: new answers to old questions. Child Development Perspectives, 8 (2): 113-118. doi:10.1111/cdep.12069

Department of Education. (2015). Special Educational Needs in England: January, 2015. DoE, London, UK.

Dionne, G., Touchette, E., Forget-Dubois, N., Petit, D., Tremblay, R. E., Montplaisir, J.Y., \& Boivin, M. (2011). Associations between sleep-wake consolidation and language development in early childhood: A longitudinal twin study. Sleep, 34(8): 987-995. doi: 10.5665/SLEEP.1148.

Djonlagic, I., Saboisky, J., Carusona, A., Stickgold, R., \& Malhotra, A. (2012). Increased sleep fragmentation leads to impaired off-line consolidation of motor memories in humans. PLOS one. doi: 10.1371/journal.pone.0034106

Duff, F. J., Reen, G., Plunkett, K., \& Nation, K. (2015). Do infant vocabulary skills predict school-age language and literacy outcomes? Journal of Child Psychology and Psychiatry, 56 (8): 848-856. doi: $10.1111 /$ jcpp. 12378.

Dunn, L. M., Dunn, L. M., Whetton, C., et al. (1997). British Picture Vocabulary Scale. 2nd edn. Windsor, Berks: NFER-Nelson.P.

Edgin, J. O., Tooley, U., Demata, B., Nyhuis, C., Anand, \& Spanò, G. (2015). Sleep disturbance and expressive language development in pre-school age children with Down Syndrome. Child Development, 86(6): 1984-1998. doi: 10.1111/cdev.12443 
Ednick, M., Cohen, A. P., McPhail, G. L., Beebe, D., Simakajornboon, N., \& Amin, R. S. (2009). A review of the effects of sleep during the first year of life on cognitive, psychomotor, and temperament development. Sleep, 32 (11): 1449-1458. doi: 10.1093/sleep/32.11.1449

El-Sheikh, M., Bagley, E. J., Keiley, M., Elmore-Staton, L., Chen, E., \& Buckhalt, J. A. (2013). Economic adversity and children's sleep problems: multiple indicators and moderation of effects. Health Psychology, 32 (8): 849-859. doi: 10.1037/a0030413

Ferri, R., Aricò, D., Bruni, O., Remington, R. W., Stamatakis, K., \& Punjabi, N. M. (2010). The effects of experimental sleep fragmentation on cognitive processing. Sleep Medicine, 11 (4): 378-385.

Ficca, G., Axelsson, J., Mollicone, D. J., Muto, V., \& Vitiello, M. V. (2010). Naps, cognition and performance. Sleep Medicine Reviews, 14 (4): 249-258. doi: 10.1016/j.smrv.2009.09.005.

Franco, P., Guyon, A., Stagnara, C., Flori, S., Bat-Pitault, F., Lin, J-S., Patural, H., \& Plancoulaine, S. (2019). Early polysomnographic characteristics associated with neurocognitive development at 36 months of age. Sleep Medicine, 60: 13-19. doi:10.1016/j.sleep.2018.11.026

Frank, M. G., Issa, N. P., \& Stryker, M. P. (2001). Sleep enhances plasticity in the developing visual cortex. Neuron, 30 (1): 275-287.

Freudigman, K.A., \& Thoman, E.B. (1993). Infant sleep during the first postnatal day: an opportunity for assessment of vulnerability. Pediatrics, 92: 373-379.

Friedrich, M., Wilhelm, I., Born, J., \& Friederici, A. D. (2015). Generalisation of word meanings during infant sleep. Nature Communications, 6: 6004. doi: 10.1038/ncomms7004.

Friedrich, M., Wilhelm, I., Mölle, M., Born, J., \& Friederici, A. D. (2017). The sleeping infant brain anticipates development. Current Biology, 27: 2374-2380. doi: 10.1016/j.cub.2017.06.070.

Gómez, R. L., Bootzin, R. R., \& Nadel, L. (2006). Naps promote abstraction in language-learning infants. Psychological Science, 17 (8): 670-674. doi: 10.1111/j.1467-9280.2006.01764.x

Gómez, R. L., \& Edgin, J. O. (2015). Sleep as a window into early neural development: shifts in sleep-dependent learning effects across early childhood. Child Development Perspectives, 9 (3): 183189. doi: $10.1111 /$ cdep. 12130

Gooch, D., Thompson, P., Nash, H. M., Snowling, M. J., \& Hulme, C. (2016). The development of executive function and language skills in the early school years. Journal of Child Psychology and Psychiatry, 57 (2): 180-187. doi: 10.1111/jcpp.12458.

Goodman, R. (1997). The Strengths and Difficulties Questionnaire: a research note. The Journal of Child Psychology and Psychiatry, 38 (5): 581-586.

Horváth, K., \& Plunkett, K. (2018). Spotlight on day-time napping during early childhood. Nature and Science of Sleep, 10: 97-104. doi: 10.2147/NSS.S126252.

Horváth, K., \& Plunkett, K. (2016). Frequent day-time naps predict vocabulary growth in early childhood. Journal of Child Psychology and Psychiatry, 57(9): 1008-1017. doi: 10.1111/jcpp.12583.

Horváth, K., Myers, K., Foster, R., \& Plunkett, K. (2015). Napping facilitates word learning in early lexical development. Journal of Sleep Research, 24 (5): 503-509. doi: 10.1111/jsr.12306.

Huber, R., \& Born, J. (2014). Sleep, synaptic connectivity, and hippocampal memory during early development. Trends in Cognitive Sciences, 18 (3): 141-152.

Hupbach, A., Gómez, R. L., Bootzin, R. R., \& Nadel, L. (2009). Nap-dependent learning in infants. Developmental Science, 12 (6): 1007-1012. doi: 10.1111/j.1467-7687.2009.00837.x.

Huttenlocher, J., Waterfall, H., Vasilyeva, M., Vevea, J., \& Hedges, L. V. (2010). Sources of variability in children's language growth. Cognitive Psychology, 61 (4): 343-365. doi: 10.1016/j.cogpsych.2010.08.002

Hysing, M., Harvey, A. G., Torersen, L., Ystrom, E., Reichborn-Kjennerud, T., \& Sivertsen, B. (2014). Trajectories and predictors of nocturnal awakenings and sleep duration in infants. Journal of Developmental and Behavioural Pediatrics, 35: 309-316.

Iglowstein, I., Jenni, O. G., Molinari, L., \& Largo, R. H. (2003). Sleep duration from infancy to adolescence: reference values and generational trends. Pediatrics, 111 (2): 302-307. doi: 10.1542/ peds.111.2.302.

Kurdziel, 1., Duclos, K., \& Spencer, R. M. (2013). Sleep spindles in midday naps enhance learning in preschool children. Proceedings of the National Academy of Sciences of the United States of America, 110 (43): 17267-17272. doi:10.1073/pnas.1306418110.

Kurth, S., Riedner, B. A., Dean, D. C., O’Muircheartaigh, J., Huber, R., Jenni, O. G., Deoni, S. C., \& LeBourgeois, M. K. (2017). Traveling slow oscillations during sleep: a marker of brain connectivity in childhood. Sleep, 40 (9): zsx121. doi: 10.1093/sleep/zsx121 
Lam, J. C., Mahone, E. M., Mason, T., \& Scharf, S. M. (2011). The effects of napping on cognitive function in pre-schoolers. Journal of Developmental Behavioral Pediatrics, 32: 9-97. doi: 10.1097/ DBP.0b013e318207ecc7.

Lassone, J. M., Rusterholz, T., Kurth, S., Schumacher, A. M., Achermann, P., \& LeBourgeois, M. K. (2016). Sleep physiology in toddlers: Effects of missing a nap on subsequent night sleep. Neurobiology of Sleep and Circadian Rhythms. 1: 19-26. doi: 10.1016/j.nbscr.2016.08.001

Lee, J. (2011). Size matters: early vocabulary as a predictor of language and literacy competence. Applied Psycholinguistics, 32 (1): 69-92. doi:10.1017/S0142716410000299.

McClelland, J. L., McNaughton, B. L., \& O'Reilly, R. C. (1995). Why there are complementary learning systems in the hippocampus and neocortex: Insights from the successes and failures of connectionist models of learning and memory. Psychological Review, 102(3), 419-457. doi:10.1037/0033-295X.102.3.419

McGregor, K., \& Alper, R. M. (2015). Sleep disorders as a risk to language learning and use. EBP Briefs, 10 (1): $1-21$.

Montgomery-Downs, H.E., \& Gozal, D. (2006). Snore-associated sleep fragmentation in infancy: mental development effects and contribution of secondhand cigarette smoke exposure. Pediatrics, 117: e496-e502.

Nieuwenhuis, R., Pelzer, B., \& te Grotenhuis, M. (2012). influence.ME: tools for detecting influential data in mixed effects models. URL: http://CRAN.P-project.org/package=influence.ME. R package version 0.9 [p.38].

Pace, A., Luo, R., Hirsh-Pasek, K., \& Golinkoff, R. M. (2017). Identifying pathways between socioeconomic status and language development. Annual Review of Linguistics, 3: 285-308. doi: 10.1146/annurev-linguistics-011516-034226

Pisch, M., Wisemann, F., \& Karmiloff-Smith, K. (2019). Infant wake after sleep onset serves as a marker for different trajectories in cognitive development. Journal of Child Psychology and Psychiatry 60 (2): 189-198.

Psyridou, M., Eklund, K., Poikkeus, A. M., \& Torppa, M. (2018). Reading outcomes of children with delayed early vocabulary: a follow-up from age 2-16. Research in Developmental Disabilities, 78: 114124. doi: 10.1016/j.ridd.2018.05.004.

R Core Team (2017). R: A language and environment for statistical computing. R Foundation for Statistical Computing, Vienna, Austria. URL https://www.R-project.org/.

Ringli, M., \& Huber, R. (2011). Developmental aspects of sleep slow waves: linking sleep, brain maturation and behavior. Progress in Brain Research, 193: 63-82. doi: 10.1016/B978-0-444-53839-0.00005-3

RStudio and Inc. (2014), rmarkdown: R Markdown Document Conversion, R package version 0.1.90, github.com/rstudio/rmarkdown

Sadeh, A., Gruber, R. \& Raviv, A. (2002). Sleep, neurobehavioural functioning, and behaviour problems in school-age children. Child Development, 73(2): 405-417. doi: 10.1111/1467-8624.00414

Sandoval, M., Leclerc, j. A., \& Gómez, R. L. (2017). Words to sleep on: naps facilitate verb generalisation in habitually and nonhabitually napping pre-schoolers. Child Development, 88 (5): 1615-1628. doi: $10.1111 /$ cdev.12723.

Scher, A. (2005). Infant sleep at 10 months of age as a window t cognitive development. Early Human Development, 81 (3): 289-292. doi: 10.1016/j.earlhumdeve.2004.07.005

Schwab, J. F., \& Lew-Williams, C. (2016). Language learning, socioeconomic status, and child-directed speech. Wiley interdisciplinary reviews. Cognitive science, 7(4), 264-275. doi:10.1002/wcs.1393

Schwartz, G. (1978). Estimating the dimension of a model. Annals of Statistics, 2: 461-464.

Simon, K. N. S., Werchan, D., Goldstein, M. R., Sweeney, L., Bootzin, R. R., Nadel, L., \& Gómez, R. L. (2017). Sleep confers a benefit for retention of statistical language learning in 6.5 month old infants. Brain and Language, 167: 3-12. doi: 10.1016/j.bandl.2016.05.002.

Smithson, L., Baird, T., Tamana, S. K., Lau, A., Mariasine, J., Chikum, J., Lefebvre, D. L., Subbarao, P., Becker, A. B., Turvey, S. E., \& Sears, M. R. (2018). Shorter sleep duration is associated with reduced cognitive development at two years of age. Sleep Medicine, 48: 131-139.

Tétreault, E., Bernier, A., Matte-Gagné, C., \& Carrier, J. (2018). Normative developmental trajectories of actigraphic sleep variables during the pre-school period: A three-wave longitudinal study. Developmental Psychobiology, 61 (1): 141-153.

Tingley, D., Yamamoto, T., Hirose, K., Imai, K. \& Keele, L. (2014). Mediation: R package for causal mediation analysis. Journal of Statistical Software, 59 (5): 1-38. URL: https://cran.r-project.org/web/ packages/mediation/mediation.pdf $\mathrm{R}$ package version 4.5.0 
Touchette, E., Cote, S. M., Petit, D., Liu, X., Boivin, M., Falissard, B., Tremblay, R. E., Montplaisir, J. Y. (2009). Short night-time sleep-duration and hyperactivity trajectories in early childhood. Pediatrics, 124 (5): e985-993. doi: 10.1542/peds.2008-2005.

Touchette, E., Dionne, G., Forget-Dubois, N., Petit, D., Pérusse, D., Falissard, B., Tremblay, R. E., Boivin, M., \& Montplaisir, J. Y. (2013). Genetic and environmental influences on day-time and night-time sleep duration in early childhood. Pediatrics, 131: e1874. doi: 10.1542/peds.2012-2284

Vernon-Feagans, L., Garrett-Peters, P., Willoughby, M., \& Mills-Koonce, W. (2012). Choas, poverty, and parenting: predictors of early language development. Early Childhood Research Quarterly, 27 (3): 339-351. doi: 10.1016/j.ecresq.2011.11.001

Werchan, D. M., \& Gómez, R. L. (2014). Wakefulness (not sleep) promotes generalization of word learning in 2.5-year-old children. Child Development, 85 (2): 429-436. doi: 10.1111/cdev.12149.

Wilhelm, I., Kurth, S., Ringli, M., Mouthon, A-L., Buchmann, A., Geiger, A., Jenni, O.G., \& Huber, R. (2014). Sleep slow-wave activity reveals developmental changes in experience-dependent plasticity. The Journal of Neuroscience, 34 (37): 12568-12575.

Williams, S. E., and Horst, J. S. (2014). Goodnight book: the benefit of sleep consolidation on word learning via storybooks. Frontiers in Psychology, 5:184. doi: 10.3389/fpsyg.2014.00184.

Wright, J., Small, N., Raynor, P., Tuffnell, D., Bhopal, R., Cameron, N., Fairly, L., Lawlor, D.A., Parslow, R., Petherick, E.S., Pickett, K.E., Waiblinger, D., \& West, J., on behalf of the Born in Bradford Scientific Collaborators Group. (2013). Cohort profile: the Born in Bradford multi-ethnic family cohort study. International Journal of Epidemiology, 42 (4): 978-991. doi: 10.1093/ije/dys112

\section{Appendix}

Table A1. Fixed effects for model of BPVS standard score. Model formed from 354 participants $(d f=4,349)$.

\begin{tabular}{lcccccc} 
& & & & \multicolumn{2}{c}{$b 95 \% \mathrm{Cl}$} \\
\cline { 5 - 7 } Term & $b$ & SE $b$ & $B$ & Lower & Upper & $t$ \\
\hline (Intercept) & 103.41 & 10.66 & & 82.52 & 124.30 & $9.699^{* \star \star}$ \\
\hline TST_B0 & -0.79 & 0.81 & -0.05 & -2.38 & 0.80 & -0.977 \\
\hline TST_B1 & -10.10 & 10.43 & -0.05 & -30.54 & 10.34 & -0.968 \\
\hline DIF_B0 & 1.60 & 0.43 & 0.20 & 0.76 & 2.44 & $3.770^{* \star *}$ \\
\hline DIF_B1 & -9.75 & 6.87 & -0.07 & -23.22 & 3.72 & -1.420 \\
\hline
\end{tabular}

Table A2. Fixed effects for model of BPVS standard score. Model formed from 225 participants $(d f=5,219)$.

\begin{tabular}{lcccccc} 
& & & & \multicolumn{2}{c}{$b 95 \% \mathrm{CI}$} \\
\cline { 5 - 7 } Term & $b$ & SE $b$ & $\beta$ & Lower & Upper & $t$ \\
\hline (Intercept) & 89.17 & 4.33 & & 80.68 & 97.66 & $20.59^{\star \star \star}$ \\
\hline DIF.6 & 0.92 & 0.50 & 0.14 & -0.06 & 1.90 & 1.83 \\
\hline DIF.12 & 1.06 & 0.53 & 0.17 & 0.02 & 2.10 & $2.02^{\star}$ \\
\hline DIF.18 & -0.49 & 0.59 & -0.07 & -1.65 & 0.67 & -0.83 \\
\hline DIF.24 & 0.47 & 0.45 & 0.08 & -0.41 & 1.35 & 1.06 \\
\hline DIF.36 & 0.43 & 0.47 & 0.07 & -0.49 & 1.35 & 0.93 \\
\hline
\end{tabular}


Table A3. Fixed effects for model of BPVS standard score. Model formed from 351 participants $(\mathrm{df}=6$, 344).

\begin{tabular}{|c|c|c|c|c|c|c|}
\hline \multirow[b]{2}{*}{ Term } & \multirow[b]{2}{*}{$b$} & \multirow[b]{2}{*}{ SE $b$} & \multirow[b]{2}{*}{ ß } & \multicolumn{2}{|c|}{ b $95 \% \mathrm{Cl}$} & \multirow[b]{2}{*}{$t$} \\
\hline & & & & Lower & Upper & \\
\hline (Intercept) & 102.17 & 10.69 & & 81.22 & 123.12 & $9.56^{\star \star \star}$ \\
\hline TST_BO & -0.83 & 0.80 & -0.06 & -2.40 & 0.73 & -1.04 \\
\hline TST_B1 & -8.60 & 10.40 & -0.05 & -28.99 & 11.79 & -0.83 \\
\hline DIF_BO & 1.34 & 0.44 & 0.17 & 0.49 & 2.20 & $3.08^{\star \star}$ \\
\hline DIF_B1 & -7.71 & 6.86 & -0.06 & -21.15 & 5.72 & -1.13 \\
\hline IMD & 1.14 & 0.39 & 0.16 & 0.38 & 1.91 & $2.93^{\star \star}$ \\
\hline Sex & 0.81 & 1.61 & 0.03 & -2.36 & 3.97 & 0.50 \\
\hline
\end{tabular}

Table A4. Linear regression models entered into mediation analysis. Significance ${ }^{\star \star \star} p<0.001$.

\begin{tabular}{|c|c|c|c|c|c|c|c|}
\hline \multirow[b]{2}{*}{ DV } & \multirow[b]{2}{*}{$\mathrm{F}$} & \multirow[b]{2}{*}{ df } & \multirow[b]{2}{*}{ Term } & \multirow[b]{2}{*}{$b$} & \multicolumn{2}{|c|}{$95 \% \mathrm{Cl}$} & \multirow[b]{2}{*}{$t$} \\
\hline & & & & & Lower & Upper & \\
\hline \multirow[t]{2}{*}{ BPVS-2 } & $13.85^{\star \star \star}$ & 1,352 & (Intercept) & 100.79 & 98.18 & 103.40 & $75.80^{\star \star \star}$ \\
\hline & & & IMD & 1.41 & 0.67 & 2.16 & $3.72^{\star \star \star}$ \\
\hline \multirow[t]{2}{*}{ DIF_B0 } & $16.09^{\star \star \star}$ & 1,352 & (Intercept) & 6.54 & 6.22 & 6.86 & $40.03^{\star \star \star}$ \\
\hline & & & IMD & 0.19 & 0.10 & 0.28 & $4.01^{\star \star \star}$ \\
\hline \multirow[t]{3}{*}{ BPVS-2 } & $12.30^{\star \star \star}$ & 2,351 & (Intercept) & 91.77 & 85.71 & 97.83 & $29.68^{\star \star \star}$ \\
\hline & & & DIF_B0 & 1.38 & 0.54 & 2.22 & $3.22^{\star \star}$ \\
\hline & & & IMD & 1.15 & 0.40 & 1.91 & $3.01^{\star \star}$ \\
\hline
\end{tabular}

Cite this article: Knowland VCP, Berens S, Gaskell MG, Walker SA, Henderson L-M (2022). Does the maturation of early sleep patterns predict language ability at school entry? A Born in Bradford study. Journal of Child Language 49, 1-23. https://doi.org/10.1017/S0305000920000677 